\title{
The junior high school integrated science: the actual teaching process in the perspective of an ethnographer
}

\author{
Kenneth Adu-Gyamfi ${ }^{1}$, Joseph Ghartey Ampiah ${ }^{2}$ \\ ${ }^{1}$ Mampong Technical College of Education, Mampong-Ashanti, Ghana \\ 2 Department of Science and Mathematics Education, University of Cape Coast, Ghana \\ For correspondence: dondonsinco@yahoo.com
}

\begin{abstract}
Science education at the Basic School (Primary and Junior High School) serves as the foundation upon which higher levels of science education are pivoted. This ethnographic study sought to investigate the teaching of Integrated Science at the Junior High School (JHS) level in the classrooms of two science teachers in two schools of differing characteristics. The two teachers were selected purposively for the study. Observations of classroom teaching and casual conversations with the science teachers for an 11 week academic term period were the main source of data for the study. The focus of the observations was on the four stages of an Integrated Science lessons of which the application stage was found to be absent in the science teachers lessons. It was further revealed among other things that the instructional hours for the teaching of Integrated Science are not the same for all schools. Hence, curriculum developers are encouraged to factor the school culture of various schools throughout the country into planning national school curriculum.
\end{abstract}

Keywords: Integrated Science, observation, science teachers, teaching

\section{Introduction}

There are 30 Metropolitan, Municipal, and District Assemblies in the Ashanti Region of Ghana. These 30 local assemblies can be grouped into one metropolis, eight municipalities, and 21 districts (Ministry of Local Government and Rural Development [MLGRD], 2012). Asante Mampong Municipality is one of the eight Municipal Assemblies in the Ashanti Region of Ghana. The Asante Mampong Municipality is endowed with all categories of schools and colleges. There are 50 Junior High Schools (JHSs), four Senior High Schools (SHSs), two Colleges of Education, one Nursing Training College, and one university campus of the University of Education, Winneba.

The common local language to almost all the peoples of the Mampong Municipality is Asante Twi as the community is part of the Ashanti community, which is one of the major tribes of Ghana. The Asante Twi is used at the market square, local community gatherings, schools and colleges, and even among government workers at official places of work. Members of Mampong Municipal community could be said to be interested in educating their young ones because as early as 6.00am author 1 observed Basic School (Primary and JHS) as well as high school pupils and students going to school. Author 1's interest in Mampong Municipality as an ethnographer was to investigate the teaching of Integrated Science with respect to the requirements of the JHS Integrated Science Syllabus. This will assist in identifying the common difficulties science teachers experience in Integrated Science lessons and the underlying reasons and possible adaptations to such difficulties. The study was therefore guided by the research question: What is the influence of school-type on the teaching of Integrated Science? 
The teaching and learning of school science at the basic education level in Ghana is considered as an important phase of science education by government and educators as well as students. This is because it lays the foundation for the interest and success in higher school science and its allied subjects and courses. The survey of Adu-Gyamfi (2013) revealed that a high percentage $(69.2 \%)$ of students at the SHS level in Ghana opt out of science and its related courses. This high percentage of students who opted out of learning of school science have simply lost interest in science; which could be attributed partly to the teaching of basic school science. In this paper we will provide a brief review of policy in Ghanaian science education and interactions of two science teachers in JHS in Mampong Municipality. We will then focus on the teaching of Integrated Science in a life class of two schools of differing characteristics. The classroom interaction data we will describe in this paper will challenge the views of policy makers on Integrated Science and the practices of science teachers in classrooms at the JHS level. This will help to improve teaching and inform policy making in the area of Integrated Science teaching and learning.

In scientific practices, the use of activities serves as the fundamentals for student learning about experiment, data and evidence, social discourse, models and tools, mathematics, and ability to evaluate knowledge and conduct investigations (Bybee, 2011). In teaching science at the lower grades, it is recommended that pictures, diagrams, drawings, and physical models could be used to develop scientific concepts and principles. However, at the upper grade levels, scientific concepts and principles which are more advanced could be developed using simulations and more sophisticated conceptual, mathematical, and computational models. Bybee (2011) pointed out that the current push towards science practices means that the teaching and learning of science-related subjects and courses should actively involve students through hands-on and laboratory work. It is then no wonder that the study of Adu-Gyamfi (2013) revealed that there is lack of interest in school science among non-science students (that is students who do not study Biology, Chemistry, or Physics as one of the 'elective subjects' at the high school level). The non-science students indicated that their lack of interest in school science was due partly to the less practical nature of the teaching and learning of scientific concepts and principles. Thus science is presented in more or less an abstract manner to students by science teachers.

There are skills that students acquire as a result of the study of school science in the schools and colleges. From Bybee (2011), the skills adopted by the students at the lower grade levels are recording and sharing of observation through drawings, writings, using of whole numbers and oral reports; whereas at the middle and high school levels the skills adopted by students establishing relationships and patterns in data, distinguishing among correlation and causation, comparing independent sets of data and confirming explanation or solution. These generic skills could be acquired through scientific investigation and experimentation in the science classroom.

According to Ali (2012), science teachers in classroom interactions with students make a lot of effort to value and explore students' relevant previous knowledge in the scientific concept for the day's lesson. This in effect means science teachers use introduction to help students to construct their meaning and understanding of the day's scientific concepts. It was further noted that teachers use demonstrations and discussion (Lapp et al., 2008; Richards and Bohlke, 2011), examples, analogies, questioning cues, probing, and prompting (Ali, 2012) for exploring and taking advantage of students' relevant previous knowledge for the day's lesson. The introductory stage of science lessons though important Yunus et al., (2004) however, observed that the introductory stage of lessons lasted for only few minutes. This was used to arouse students' interest and curiosity in the new lesson. At the introductory stage, students' previous knowledge with respect to the new lesson is being sought but not students' ideas about the new lesson. Richards and Bohlke (2011) were of the view that the opening of a lesson should be used to partly bring the attention of the students to the objectives of the lesson. 
Lapp et al. (2008) explained that students' knowledge construction is aided by the creation of learning environment by teachers (Richards and Bohlke, 2011), which is more interactive to that of learning environment which is more of information given by the teachers where the students are only recipients. The interactive learning environment enables the students to be engaged in a conversation which facilitate thinking and sharing of ideas about scientific concepts and principles. Ali (2012) identified that students' tensions and difficulties evolve whenever in the classroom interactions with the science teacher they find themselves not being able to give meaning of some scientific concepts, describe ideas, make conceptual connections, explain their viewpoint, and ask questions. This could be that they are disappointed in themselves or think that they are failing their teacher by not doing enough in such situations. One of the failures of Science Education at the high school level is how to use classroom practices to develop and sustain students' interest in science for them to show positive attitude towards the subject, science. Therefore science teachers are of the view that every student is of some abilities and if enhance by providing them with opportunities will help him or her to do everything. This shows that students only need guidance from the science teacher to enable them construct their own meaning and understanding about scientific concepts and principles. Science teachers are aware of the students' difficulties in learning science and hence, demonstrated that they have the knowledge and the skill to help minimise the negative effects of such difficulties on student learning of scientific concepts (Ali, 2012).

Zander (2013) observed that in a typical Intensive English Center in the US there is a mixture of students of different first language background and English Language as a second language. Students of bilingual status oscillate between the two languages for clarification of scientific concepts under discussion. This means that bilingual students co-construct scientific knowledge through the oscillation between the first and second languages (Choi and Kuipers, n.d.). Elloitt (2010) appreciated from the literature that much of the science curriculum language is new to students as words with scientific meanings are usually not experienced in everyday life. Elloitt therefore recommended that science teachers should identify and explore such scientific words by allowing the students to repeat such words aloud and spell them as well.

According Lapp et al. (2008), science teachers use classroom practices and students' experiences to teach the scientific concepts. Thus after every point developed, the students were made to related it to an experience or characteristics they might have once encountered. This seems to have worked well as the paper of Lapp et al. (2008) showed that the students were able. For instance, a student was able to associate the light and sound from a chemical change with that of the fireworks he has once observed.

Classroom discussions being it teacher-led discussion or student-group discussion are usually short of sense-making and persuasive nature of scientific argumentation (Driver et al., 2000). And for this reason, Berland and Reiser (2011) sought to have created a classroom discussion setting that enabled students to participate and practice scientific sense-making and persuasion in their study.

Curriculum planning and designing go with implementation and the study of BouJaoude and Saad (2012) with the teachers in Lebanon schools has revealed that the teachers are the implementer of a national curriculum and that whatever they teach is governed by the prescribed curriculum. The teachers were however allowed to select their own methods of teaching that to their professional view point suits the scientific concept for that day. The teaching methodology adopted by science teachers affect the intended implication of any curriculum since it creates conflict amongst the curriculum aspirations for science classroom practices and the observed patterns of classroom interactions (Yunus et al., 2004). 


\section{Research Site, Participants, and Methods}

This is an ethnographic study we carried out with some Basic Schools (JHSs) in Mampong Municipality of the Ashanti Region of Ghana. Mampong Municipal is basically an Ashanti community with majority of the people; both the schooled and unschooled speaking the Asante Twi. The inhabitants are not necessarily all Ashantis but could be comprising almost people from all the other nine regions of Ghana.

In Mampong Municipal, schooling could be described as an attractive thing as all spheres of educational institution are present in the municipality. There were 50 JHSs comprising of seven Private Institutions and 43 Government-Assisted Institutions. In the Mampong Township where the study was carried out, there were 17 JHSs out of the 50 schools in the municipality with five Private Institutions and 12 Government-Assisted Institutions. The schools in Mampong Municipality are categorised into endowed and less-endowed institutions with respect to the infrastructure and facilities present in each school as well as the willingness of parents or guardians to send their wards to such school.

Two school sites from which one from endowed and less-endowed was used for the study. The two schools were selected purposively partly because of the categories they belong to and the willingness on the part of the schools' authorities and science teachers to participate in the study. In each school author 1 was welcomed by the head of science department who then introduced me to the other members of the department where applicable and later to the headteacher. Author explained to the headteachers the purpose and the benefits of the study to the schools and education in the country as a whole. The heads were happy and later introduced author 1 to the other members of staff. Author1 was introduced to the students as a mentee who has come to understudy the teaching of Integrated Science from their science teachers in the third week of the third term of the 2012/2013 academic year.

The two science teachers described in the study were selected purposively from four science teachers from the two schools. This is because in the less-endowed school there was only one science teacher who agreed to participate in the study and in the endowed school, there were three science teachers and the one described in the study willingly accepted to participate in the study. The teachers seemed to be experienced professional science teachers at the JHS level as they have spent a minimum of five years in the teaching of Basic School Integrated Science. This is because the teachers have had pre-service teacher training education from either one of the 38 Government Colleges of Education in Ghana and have top it up to have obtained degree in education certificate from one of the universities in Ghana. The teachers were observed teaching Integrated Science for a Basic School Term of 11 weeks.

Author1 employed a number of modes of data collection in the collection of data in this ethnographic study. Author made visits to the schools three times each week from the fourth week to the tenth week. The eleventh week was not included because it was an examination week and the first three weeks of my classroom observation of Integrated Science teaching was not included as part of the data for the study as author thought the teaching and the teaching environment could have been organised to satisfy my curiosity and hence, not a naturalistic setting as required by the tenants of ethnography. Data collection modes included observation of classroom teaching and learning of Integrated Science, observation of lesson notes and school time tables, and casual conversation with the science teachers after each observed lesson. The records of JHSs and teacher distribution in the municipality together with the Integrated Science Curriculum and some records of the MLGRD were also observed. 
The classroom observation schedule employed in this study was in line with the four stages of an Integrated Science Lesson Plan developed in Ministry of Education, Youth and Sports [MOEYS] (2006) handbook, which is a material used in training teachers from the Colleges of Education for Ghanaian Basic schools. The four stages are partly in agreement with the observation schedule adapted by Yunus et al. (2004) from Smith and Neale. The four stages used here are:

1. Introduction, which is considered to be the first teacher-learner activity during the lesson. It creates a linkage between the learners' previous knowledge and the new scientific concept or principle.

2. Presentation/Development; is the stage where the science teacher shows the learners how to perform the skills they want to be proficient in or the scientific facts, concepts, and principles they seek understanding.

3. Application, which is the stage where the science teacher provides the learners with the opportunity to apply the scientific knowledge acquired in solving problems.

4. Closure; is the stage where the science teacher ensures that the learners have mastered the scientific knowledge acquired. It is at times referred to as the post-presentation stage and is achieved partly through review of the lesson with oral question and answers or written exercise on the evaluation exercise. At the closure stage some room is given for learners to write down the scientific knowledge developed in the day's lesson.

It could be said that this observation schedule gives science teachers the room to select the appropriate methods of teaching and learning, teaching and learning materials (TLMs), and the content. Thus science teachers are able to demonstrate their pedagogical content knowledge in science lessons by considering the students' difficulties in learning as propounded by Shulman (1987). The main mode of observation was field notes which were later developed into summary observations. In addition to the observation modes of data collection, casual conversation with the science teachers was adopted as it made teachers feel free and natural in whatever they were saying. It could be said that rich data were obtained for the study as a result of the casual conversation authorı made with the teachers.

\section{Policy}

The rationale for teaching Integrated Science at the JHS level was to create scientific culture. For the scientific culture to be achieved with respect to the country's strategic programme of achieving scientific and technological literacy in the shortest possible time, one of the two aims of the syllabus was to produce competent professionals in various scientific disciplines to be able to conduct investigation at the highest level. This then required that students be trained to physically explore and discover knowledge with their environment and the laboratory (Ministry of Education [MOE], 2012). Hence, one of the positive attitudes and values expected to be developed by students was "curiosity to explore their environment and question what they find" (p. ii) as they experience the JHS Integrated Science Curriculum.

From MOE (2012), a total of six period lessons per week were expected to be assigned to the teaching of Integrated Science at the JHS level. Each of the six periods should be 40 minutes and hence, 240 minutes (that is 4 hours) of students' instructional hours should be used to teach Integrated Science at the JHS level. Amongst the six periods, it was expected that the teaching of theory be given four periods and the teaching of practicals be given two periods per week. All Integrated Science lessons should be double periods, which is 80 minutes.

It was recommended among other things that for effective teaching and learning of the JHS Integrated Science, every school should have science equipment and materials for the students to interact with during Integrated Science lessons (MOE, 2012). Provision of science equipment and materials should 
not be a recommendation but should be provided by the government as without them will render the teaching and learning of Integrated Science abstract in nature but students at the JHS level are supposed to interact with materials as they learn science. And the policy of weekly double period for practical Integrated Science will not be implemented to the letter.

MOE (2012) was convinced that any Ghanaian Integrated Science classroom could be a mixture of different ability groups (such as high and lower achievers, slow and fast learners, and those that are unable to spell or read). The MOE therefore recommended that such special students need respective attention to enable each student learn and develop his or her abilities in Integrated Science.

Another tentacle of the policy as stated by MOEYS (2004) is that the government of the Republic of Ghana accepts that children's first home language (L1) and Ghana's official language, English Language (L2) should be the medium of instruction for the lower primary. This is because the L1 is an effective communication tool for teaching and learning at the lower primary. The Ghanaian government therefore emphasize that the L1 should be the dominant medium of instruction at the lower primary; as scientific research has proven beyond reasonable doubt that at lower primary the L1 contributes a lot to the child's educational development.

For the Ghanaian child to be balanced, the government of Ghana appreciates that there is the need for citizens of Ghana to be well established in L2 and even a third or fourth language. Hence, the early introduction of L2 at the early stages of the citizens development at the lower primary and increasing used at the high school level. This will help the citizens to attain good working and communication skills in L2 (MOEYS, 2004).

\section{Teaching of Integrated Science: The Classroom Interactions of Two Science Teachers}

\section{Case Study 1}

School A was one of the less-endowed schools in Mampong Municipality with 125 student population. Majority of these students could be said to come from the lower social class as their school uniforms and the way they carried themselves showed. The school was a two-stream institution for all year groups with the exception of the third year group, which was a single stream. Christian Odoi was the only science teacher of the school, and hence handled all the topics in Integrated Science for the school for all year groups. The classroom interactions of Christian in one of the first year classes of 26 students are being reported as part of this study. There were eight male students compared to 18 female students in the same class. From the schools' time table, each instruction period was 40 minutes and there were three double periods of Integrated Science lessons for each class. This is in agreement with the number of periods required for teaching Integrated Science by MOE (2012). However, there was no indication of double period for practical lessons as required by MOE (2012) on the time table which could imply that it was not demanded of Christian by the school authorities to conduct laboratory practical work. This was attributed to the fact that there was no science laboratory with the required science equipment and materials to enable the science teacher organised the practical sessions for the students. However, environmental explorations and investigations to acquire scientific knowledge were possible because of the vast land that seemed to be available to the school.

One of the stages of any JHS Integrated Science lesson, which is also one of the focuses of the observations reported in this paper, is introduction. At the introductory stage of Christian's lessons, he usually reviewed the students' previous scientific knowledge which had direct link with the day's lesson. The teaching techniques adopted by Christian at the introductory stage were basically question and answer, creation of situations, and activity. Below is an introductory extract from an observation in Christian's class using the question and answer technique together with activity: 
T: Group students and give out materials

Ss: Receive materials

$\mathrm{T}$ : Light the candle as this and observe what happens

S: The candle was melting

T: Pour the 'liquid' on the table top

Ss: Pour

T: What did happen?

S: The liquid (molten wax) has changed to solid

T: Good

$\mathrm{T}$ : How did the molten wax change to solid?

S1: No idea

S2: by the passage of air over it

$\mathrm{T}$ : Before that, what happened?

The students could not give the exact concept their teacher was looking for and the teacher reacted as

T: Heat in it has been taken out

T: Was there any change in state to the candle?

Ss: Yes

T: How?

S1: It changed from solid state to liquid state

T: Was there any change to the candle as a substance?

Each group should discuss among themselves and give out one answer

G1: No change

T: Why?

G1: The candle was obtained back

G2: Yes; because the wick is no longer there

G3: No; because the substance there is still the same as candle

$\mathrm{T}$ : There was no new substance form as the substance remains the candle wax we stated with. Christian then used the day's activity and an illustration of the changes of state of water to land on the day's lesson as physical change.

Where $\mathrm{T}=$ teacher, $\mathrm{S}=$ student, $\mathrm{Ss}=$ students, $\mathrm{G}=$ group

In my conversation with Christian after the lesson as we used to do, he said that the concept of change of state of matter has been introduced to the class in the previous lessons and that was why he decided to take the students through such as activity to introduce the new lesson. The students were active in the lesson and from their faces; it seemed the students were happy and willing to see what was ahead in the lesson.

The time spent during this introduction to the concept of physical change was close to 15 minutes and this could be attributed to the activity-nature of the introduction. However, in cases where only the question and answer technique was used, it took Christian less than 15 minutes to introduce his lesson in any of his 80 minutes lessons author observed. Christian revealed to author that too much time should not be spent at this stage of the lesson as it is just a preparatory stage of the lesson. "The lesson delayed here because of the activity involved in reviewing the students' previous knowledge". Christian said this in responding to the question: Why did you seem to have spent a lot of time in introducing your lesson today?

After the introduction, Christian went on to present the new knowledge where the students sought for understanding. He employed varying teaching and learning methods such as activity, discussion, demonstration, and question and answer in teaching scientific concepts to the level of the students. Christian made known the objectives of the each lesson to the students, one after the other. That is he 
gave out objective one and work towards achieving it before making known the second objective; systematically building the core points on the chalk board. The students were allowed to write the core points into their books as he wrote them on the chalk. Authorı went on to ask Christian: "why do you allow your students write down points after you as you write on the chalk board but not at the end of the lesson?" Christian responded by saying this: "it prevents boredomness; as the students write they read over; and it helps the students to follow through the day's lesson."

The use of L1 was a major communication tool of Christian's teaching of Integrated Science. However, what was stated in using the L1 was immediately stated in the true instructional medium that is L2, recommended for teaching pupils and students from the upper primary and beyond (MOEYS, 2004). An extract of Christian's lesson where the L1 can be seen is:

$\mathrm{T}$ : What is the meaning of shade in Asante Twi (L1)?

S: 'onwonu'

T: Very good

Ss: Realised the meaning of the concept of shading

$\mathrm{T}$ : What then is the meaning of the cultural practice shading?

S: Is like using palm fronds to build a canopy over the vegetable seedlings

T: that is correct

Later in author's conversations with Christian authorı made some enquiries from Christian on his idea on the medium of instruction:

E: Why do you use Asant Twi together with English Language in teaching and even encourage your students to speak Twi?

C: For the students to understand and appreciate the scientific concepts in their local language. The use of the local language speeds up the teaching and learning process as you have seen

E: Are you not denying them proficiency in the L2?

C: Sir; what is the use if I teach and my students cannot understand what I'm teaching them. Do you know that in the class there are students who find it difficult to read or write and all such students need to understand the scientific concepts I'm teaching.

Author1 observed that when your students cannot answer or explain their answers to your questions they usually felt unhappy and tried as much as they could to give out their best. Christian contributed to the conversation by saying that is true and in such situations, I felt I should use prompt questions and even at times use the L1 to assist the students to answer or explain the concept they were trying to answer or explain. This worked well in most situations as such prompt questions and the use of L1 helped students to respond right to the question or the discussion.

There was some level of tolerance and accommodation of students' weaknesses in learning science. Especially, when the lesson was that of activity-based, Christian managed to attend to each individual needs not considering how long it took him. For instance, during his lesson on 'adaptation', there was a time the students had to draw and label a side view of a fish; Christian inspected every students drawing one after the other and even coaching them as well. When he appreciated that the majority of the class cannot draw; he came to the chalk board and demonstrated to the students on how to obtain the outline of a fish. At a certain point in time he showed the work of some students who have had it right to the other students encouraging them to work harder as it was possible for them to draw looking at what their colleagues have done. Christian concluded this conversation by saying: "I accommodate and interact freely with my students because students are usually of the view that science is a difficult subject and by adopting such posture will enable my students to freely ask and answer questions and actively participate in my lessons". These revelations came in when Christian was responding to author1's questions: "why do you accommodate your students in such a manner? You always show them a friendly face, why?" 
The application stage of any Integrated Science lesson as it should have been present as the third stage (MOEYS, 2006) was absent in Christian's lessons author observed. At point during the field observations, authorı collected Christian's Lesson Note Book, which contained almost all the lessons he has prepared for the term and found out that there was no issue on the application stage. He only told me that he try as much as possible to give his students test items that are application oriented but not factor it as one of the stages of the lesson.

The closure of Christian's lesson was used commonly for summarising the knowledge acquired for the day. This was done in consonance with the lesson objectives. There were some moments of written exercises at the closure stage. The moment of the written exercises seemed to be happening because of the manageable class size he has. The written exercise technique used at the closure was only carried out at instances where there were 10 minutes or more left and this was in agreement with what was written in his lesson plan. There were also few instances where the closure aspects were not carried out as expected. This was because Christian was catch up by the bell. He said that these are 'necessary evils' which at times are bound to happen.

\section{Case Study 2}

Malik Mensah was one of the three science teachers in School B which is considered as an endowed school. The school was situated in a school complex of basic school, second cycle school, and a tertiary institution. At the time of the study the school population of students stood at 578 . The 578 students were not necessarily inhabitants of Mampong Municipality but from almost all corners of the country. They seemed to be the wards of middle or the wealthy class of the society. This is because such people of the Ghanaian society could afford the demands of such institutions, put their wards in a boarding house, or transport their wards from far and near to the school campus. The school was a four stream institution and Malik was assigned to the second year group. An interaction in a second year class consisting of 20 males and 31 females; totaling 51 students was used partly for this study. From School B's time table, a double period was 60 minutes long which is 20 minutes less than the required minutes for a double period of Integrated Science lesson (MOE, 2012). All the six periods allotted to the teaching and learning of Integrated Science was used for the theoretical aspects of science lessons with no indication of science practical periods on the time table. When author 1 enquired from the science teacher: Do you conduct practical lessons with you students? Christian had these to say:

When there is the need to have practicals, we carry them at the secondary school laboratories as we have no science laboratories of our own. We have just had practicals at the secondary school laboratory on food test under photosynthesis. We only bring the materials to our classrooms for practicals when such practical activity has no heating element involved.

This means the Malik's school is just fortunate of being part of a school complex where access to school laboratory is not difficult, and hence the absence of practical periods on the school time table means Malik and his two other colleagues decide when to organise practical lessons for their respective students as demanded by MOE (2012).

Malik introduced all his lessons that author observed. The main teaching technique adopted by Malik at his introductory stage was the question and answer. The introduction was used to review previous lessons which have direct bearing on the new scientific concept. An introduction extract of one of Malik's lessons relating to food test was:

T: Our previous lesson was on test of starch

Ss: yes

$\mathrm{T}$ : What is the nature of the equipment used to pour the iodine solution on the food? 


\author{
S: dropper \\ $\mathrm{T}$ : Which type of dropper? \\ Ss: is referred to as a dropper. \\ Students could not answer the question correct as expected by Malik \\ T: Is pipette dropper \\ T: Explain why iodine solution on fresh cassava will not change colour? \\ S: The cells are not dead and it must be cooked first
}

The introduction of this lesson lasted for 10 minutes and most of Malik's introductions were within this time period of his 60-minute lessons. The teacher said that too much of the minutes of the day's lesson should not be 'consumed' at the introductory stage as it is not the actual job for the day but it must be done in such a way that it will help to prepare the minds and the make the students ready for the new scientific knowledge.

The next stage of Malik's lesson was the development; which was devoted to the presentation of the new scientific knowledge where the students were to develop proficiency. Malik having finished linking the students' previous knowledge with the new lesson, he then drew the attention of the students to the specific objectives for the day's concept. For instance, on the concept circulatory system he has these objectives to achieve at the end of the 60 minutes lesson:

By the end of today' lesson we are expected to:

1. explain the concept of circulatory system in humans;

2. draw and label the longitudinal section of the human heart; and

3. outline the functions of the parts of human heart.

Such objectives in Malik's lessons were observed being achieved systematically one after the other employing various teaching methods such as discussion, question and answer, demonstration, and situational illustrations. The lessons were systematic because the new scientific knowledge was developed with respect to the stated objectives for that day; building the core points which reflected the objectives on the chalk board. As Malik wrote the core points on the chalk board, the students wrote after him but immediate ordered the students to stop writing and join the class discussion or activity working towards achieving the next objective. Author 1 enquired from Malik that "why do allow your students to write core points after you whenever you write on the chalk board?" He said: "It helps to involve the students in the lesson and to prevent boredomness."

Throughout the lessons author 1 observed, Malik demonstrated his control over the subject matter explaining concepts to the levels of the students and from the look of things the students seemed happy and interested in the lessons. This could imply that the students understood whatever their teacher was teaching as they were able to answer higher percentage of the questions that Malik asked in the course of teaching. However, Malik only adopted the L2 as the medium of instruction in all his lessons without a single used of the L1; and author 1 wondered. So in one of our conversations, author1 enquired as reported here:

E: Why do you use only English Language throughout your lessons?

M: It is the policy of the school that except during the teaching and learning of Ghanaian Language (L1), the L2 should be the medium of instruction for the teaching and learning of all subjects

E: Do students really understand your lessons?

M: Yes and you have witness it yourself.

Where $\mathrm{E}=$ ethnographer; $\mathrm{M}=$ Malik

Though Malik's lessons were lively and active, there was the problem of class control as the class was observed to be quite noisy. This was due to the large class size of 51 students where almost 
everybody was trying to catch the attention of their teacher. Notwithstanding the large noisy class author1 observed, Malik was accommodating with respect to the attitudes of his students in the classroom. For instance, at the beginning of one of Malik's lessons on "food test", the students brought a live bat they just found behind the classroom into the class but he had time to discuss and satisfy the students' curiousity. He told the students:

Bat is a mammal with wings modified from the forelimbs and has hairs on the body. The bat is one of the echolocation animals, which observes objects with the help of the sound emanating from the object. It also adapt to its environment with the wings for flying and the long-large ears for hearing.

Malik then allowed the students to observe some of the identifiable parts of the specimen. This is an extract of the interactions that ensued thereafter:

$\mathrm{T}$ : Why is bat considered as mammal?

$\mathrm{S}$ : Because it breast feeds the young ones like human beings

T: What other mammal has well developed ears for hearing?

Ss: Rabbit

T: What do bats feed on?

Ss: No answer

T: Fruits

From the facial expression of the students thereafter, author could say that the students were more than happy from their teacher's accommodation and demonstration of knowledge of subject matter. They were then poised for the day's lessons. At the end of the lesson and on our way back to the staff common room, author1 asked Malik; "why do you accommodate your students in such a manner? You always show them a friendly face, why?" Malik then have this to say:

I want my students to be happy in class and develop interest in science. I do show friendly attitude towards my students so that they will miss me when I'm not in school; and even when I'm in school, they will be ready and willing to learn science.

Malik's lessons as well as his lesson plans were without the application stage of the Integrated Science lesson. Malik said that he hardly consider the application stage when he is preparing his lesson plan to have it formally written down but incorporated it in teaching. This is because some questions are in the application domain.

The last stage of Malik's lessons was the closure. He used usually the last 5 minutes of each lesson to summarise his lesson with respect the objectives set. Mlaik hardly conduct written exercises at the end of the lessons because of the large class size and other reasons which are not reported in this article. There were some occasions that his lesson was beaten by time where the closure was not carried out. "These at times happen whenever the class interactions become so intense that I only have to give room for my students enjoy the lesson". He said this as the justification for his inability to satisfy the closure aspects of his lessons as he has planned for.

\section{Discussion}

It was found out that some JHSs use 40 minutes science lesson and others use 30 minutes science lesson. The 30 minutes lesson is not in consonance with the policy on the number of minutes for an Integrated Science lesson. This could imply that the implementation of any Ghanaian school curriculum is left in the hands of the implementers, herein the educators as it is in other parts of the world (BouJaoude and Saad, 2012). The short of some minutes in the teaching of integrated Science in some of the schools in Ghana may be due to reasons which this current study could not identify. 
The finding that the JHSs are without science laboratories for the practical lessons of Integrated Science show that the JHS Integrated Science lessons cannot be dovetailed into the assertion of Bybee (2011) that there is current push towards science practices. This means that the requirement of the Integrated Science Syllabus for students to be trained to explore and investigate scientific concepts in the laboratory (MOE, 2012) could not be met in the current scheme of things.

The findings from the study have shown that the introduction of an Integrated Science lesson is used basically to review a previous lesson which is closely related to the new scientific concept to be learnt; through the use of question and answer technique, creation of situations, and activity-based techniques. This has been seen to prepare the students minds towards the new scientific concept and energise them to be active in the lesson. This confirms the observations of Ali (2012); Lapp et al. (2008); Richards and Bohlke (2011) that science teachers in classrooms interact with students by valuing and exploring the students' relevant previous knowledge in the scientific concept for the day's lesson through question and answer, demonstration, and activity.

From the study, less than one-fourth of the instructional minutes for Integrated Science lessons are used to review students' previous knowledge relating to the new scientific concept to be learnt. Yunus et al. (2004) made similar observation that the introductory stage of lessons lasted for only few minutes. And the purpose was to arouse the students' interest and curiosity in the new lesson. There is then no need of experiencing friction at the introductory stage as students' previous knowledge with respect to the new lesson is being sought for but not students' ideas about the new lesson, hence few minutes could be enough for the review of students' previous knowledge.

The observations have shown that science teachers read out or make known the objectives of their lessons to the students at the beginning or as the lesson progresses. This goes on to add to the current debate on whether the specific objectives for a particular lesson should be made known to the students or not. However, like the findings of this ethnography, Richards and Bohlke (2011) agreed that the opening of a lesson should be used to bring the attention of the students to the lesson objectives.

From the findings of the study, it could be appreciated that some JHSs are strictly implementing the use of L2 as the medium of instruction for teaching all other subjects except the Ghanaian Languages (MOEYS, 2004) whereas other JHSs fail to implement the language policy to the letter. This could be attributed to the fact that the Ghanaian classrooms are mixture of students of differing trait (MOE, 2012); with English Language as the second language as observed in some other parts of the world (Zander, 2013). For cases where there is strict implementation of the medium of instruction for upper primary and beyond could be attributed to the multilingual nature of the school environment and the quality of the students present in the school. For the less-endowed JHSs as the one reported in this study, the strict implementation of language policy could be a difficult task as some of the students have difficulty in reading and learning using the L2, and hence the strict use of L2 as the medium of instruction could have adverse effect on students in learning science. Students from the less-endowed school have to make meaning in the L1 in order to appreciate the scientific concept in the L2. This means that bilingual students co-construct scientific knowledge through the oscillation between the first and second languages (Choi and Kuipers, n.d.).

Another finding of the study is science teachers' accommodative attitudes towards students in diverse ways in the Integrated Science class. This kind of attitude adopted by the science teaches created friendly environment with which students could be happy, develop interest in science, freely ask and answer questions, and actively take part in the interactions in the science classroom. This indeed is true as Richards and Bohlke (2011) revealed that teachers play vital role in creating 
conducive learning environment in the classroom which will encourage students to construct new scientific knowledge (Lapp et al., 2008).

From the observations of the study, it was found that the science teachers hardly prepare their lessons incorporating the application stage. And this could be said to be a revelation as the teachers are admonished at the Colleges of Education level to factor the application of the new scientific knowledge students have acquired in a new lesson. This is because the importance of application stage to the acquisition of new scientific knowledge cannot be over emphasized. Application enables students to relate the scientific knowledge to everyday life; concretises learning; and helps in problem solving.

It was also found out that the closure stage of the science teachers' lesson plan is basically used to summary the day's lesson in line with the objectives. It is also used for the conduction of some written exercises. As a result of the summary or the written exercises, teachers assess the extent to which they have achieved the lesson objectives. The act of assessing the achievement of the lesson objectives means teachers are also determining the how well students have master the new scientific knowledge.

Another finding show that science teachers at the JHS level demonstrated strong subject knowledge in the teaching of Integrated Science. This is seen in how they presented scientific concepts systematically in line with the lesson's objectives to students and responded to students' questions. Even when teachers were not prepared to present such concepts but were confronted with, teachers did their best to satisfy students' curiosity without compromising on the quality of the scientific knowledge expected.

\section{Conclusions}

The instructional minutes for the teaching of Integrated Science per week, which in theory is 240 minutes are not the same for all schools in practice. This in any case could not be said to be affecting the teaching of Integrated Science as the teachers in the schools have adapted to the quantum of the instructional minutes allotted to the subject. This then could imply that curriculum developers should factor the culture of the various JHSs into planning national school curriculum.

The study has shown that there are no science laboratories for the schools at the JHS level and science practical lessons are not usually part of the Integrated Science teaching and learning. This confirms the findings of the study of Adu-Gyamfi (2013) which reveal the lack of interest in school science among non-science due to the less practical nature of science lessons. It is therefore recommended that the Ministry of Education and the Ghana Education Service should assist institutions at the JHS level to put up science laboratories to facilitate practical teaching and learning of Integrated Science.

The introduction stage of Integrated Science lessons at the JHS level is used to review the students' previous knowledge which necessarily is/are the concept or concepts that have been introduced and learnt by students in a previous lesson and is directly related to the new scientific knowledge. The techniques used for the introduction are question and answer, creation of situations, and activity. Amongst the common techniques used by the science teachers, the activity-based technique is time consuming. Though activity-based introduction could be time consuming but science teachers should as much as possible incorporate it into the introduction of their lessons and not only use questioning and analogies to explore students' previous knowledge (Bybee, 2011). Hence, activity-based introduction could help develop in JHS students the attitudes and values of experimenting, investigating, and questioning everything within their environment, which are what the Integrated Science Teaching Syllabus is hoping for (MOE, 2012). 
The study has shown that language is an important tool in the teaching and learning process of Integrated Science. This is because it is the means of oral and written communication in the science classroom. The use of the first language in a bilingual or multilingual community is found to be helpful in teaching Integrated Science in one breadth; however the strict adherence to the use of the second language as the only means of instruction also works very well in another breadth. It is therefore recommended that in bilingual or multilingual society; one language can be adopted being it L1 or L2 as the medium of instruction. When this is strictly observed by the implementers of school curriculum, then there would not be any need for oscillating in between two languages as medium of communication. Science educators should therefore be mindful of the fact that their teaching methodology has direct repercussion on the implementation of science curriculum; and if care is not taken could create conflict between the curriculum aspirations and the observed classroom interactions (Yunus et al., 2004). To further add to it, science teachers could identify and explore the new scientific words by allowing students to repeat such words aloud and even spell them as well when they identify that their students have communication problems in the L2. This is because the science curriculum worldwide has been identified to be full language which is new to students and not experienced in everyday life (Elloitt, 2010).

The study has also shown that science teachers create enabling environment for students to develop and show interest in science which is in disagreement with findings of Ali (2012) where science education is considered to have failed at the high school level in using classroom practices to develop and sustain students' interest in science for them to show positive attitude towards the subject, science. It is therefore recommended that science teachers should do their possible best to tolerate and warmly welcome students into science classes to make them willing and ready to acquire scientific knowledge.

The study has showed that among the four stages of Integrated Science lesson plan as accepted for use by Ghanaian JHSs, the application stage is usually not considered and used by the science teachers. It therefore behooves on circuit supervisors and headteachers to organise seminars and workshops on science lesson plan and stress the importance and the need of the application stage of JHS Integrated Science to science teachers. This is because elsewhere science teacher used classroom practices and students' experiences to help students construct new knowledge (Lapp et al., 2008).

The closure of the lesson is as important as any other stage of the Integrated Science lesson. This is because it used to assess the success or other wise of the day's lesson. Like the introduction of the lesson, the closure of the lesson is given very small fraction of the percentage time allotted for the Integrated Science lessons at the JHS level by science teachers. By convention, science teachers partly allow students to write down the new scientific knowledge they have acquired as core points into the note books at the closure stage but this study has showed that science teachers prefer their students to write core points after them as they build the points on the chalk board at the development stage notwithstanding the school-type in question. This is because at the development stage the writing of core points help to engage students and make them active in the lesson.

It can be said that an Integrated Science lesson consists of four stages (introduction, development, application, and closure) which work together towards achieving the objectives set for the lesson. The success of an Integrated Science rests on how well these four stages are handled before and during the lesson. Science teachers from all school-types are therefore encouraged to carefully consider all the stages whenever they are preparing their lessons. This is because the quality of the content of scientific knowledge presented to students should be same in all schools and colleges at the same level through the country. 
The study has shown that notwithstanding the school being endowed or less-endowed science teachers do not compromise on the quality of scientific knowledge students are expected to acquire. Science teachers irrespective of the difficulties their schools present, manage to adapt to the school environment with respect to the quality of students present and materials available to present scientific knowledge to students.

\section{References}

Adu-Gyamfi, K. (2013). Lack of interest in school science among non-science students at the senior high school level. Problems of Education in the 21 $1^{\text {st }}$ Century, 53(53), 7-21.

Ali, T. (2012). A case study of the common difficulties experienced by high school students in chemistry classroom in Gilgit-Baltistan (Pakistan). sgo.sagepub.com/content/2/2/21583440124471 99.full.pdf $+\mathrm{html}$, (accessed February 2013)

Berland, L. K., and Reiser, B. J. (2011). Classroom communities' adaptations of the practice of scientific argumentation. Science Education, 95, 191-216.

BouJaoude, S., and Saad, R. (2012). The relationship between teachers' knowledge and beliefs about science and inquiry and their classroom practices. Eurasia Journal of Mathematics, Science E Technology Education, 8(2), 113-128.

Bybee, R. W. (2011). Scientific and engineering practices in K-12 classrooms: Understanding a framework for K-12 science education. www.nsta.org/about/standardsupdate/resources/201112_Framework-Bybee.pdf, (accessed July 2013)

Choi, J., and Kuipers, J. (n.d.). Bilingual practices in a science classroom: Bilingual Hispanic students' ways of constructing school science. www2.gwu.edu/ scale-up/documents/ EQRE.pdf, (accessed July 2013)

Driver, R., Newton, P., and Osborne, J. (2000). Establishing the norms of scientific argumentation in classrooms. Science Education, 84, 287-312.

Elloitt, P. (2010). Science and literacy in the elementary classroom. What Works? Research into Practice. www.edu.gov.on.ca/eng/literacynumeracy/inspire/research/WW_science_literacy.pdf, (accessed July 2013)

Lapp, D., Fisher, D., and Grant, M. (2008)."You can read this text - I'll show you how": Interactive comprehensive instruction. Journal of Adolescent \& Adult Literacy, 51(5), 372-383.

Ministry of Education. [MOE]. (2012). National syllabus for integrated science for junior high school. Accra: Curriculum Research and Development Division.

Ministry of Education, Youth and Sports. [MOEYS]. (2004). White paper on the report of the education reform review committee. Accra: MOEYS.

Ministry of Education, Youth and Sports. [MOEYS]. (2006). Methods of teaching integrated science. Accra: Teacher Education Division, Ghana Education Service.

Ministry of Local Government and Rural Development. [MLGRD]. (2012). Metropolitan, municipal and district assemblies in Ghana: MMDAs chart. Accra: AFS, MLGRD.

Richards, J. C., and Bohlke, D. (2011). Creating effective language lessons. Cambridge: Cambridge University Press.

Shulman, L. S. (1987). Knowledge and teaching: Foundations of the new reforms. Harvard Educational Review, 57(1), 1-21.

Yunus, H. M., Ismail, Z., \& Raper, G. (2004). Malaysian primary teachers' classroom practice of teaching and learning science. Journal of Science and Mathematics Education in S. E. Asia, 27(1), 166-203.

Zander, R. (2013). Ethnography of polite and impolite student classroom behaviour in the intensive english center. Linguistic Portfolios, 2(11), 115-130. 